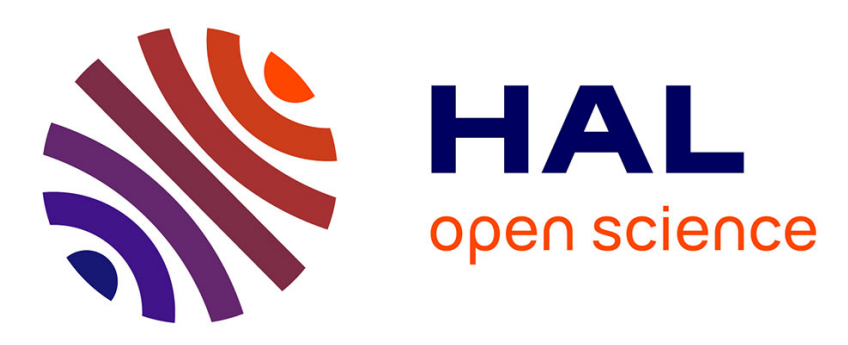

\title{
Dexamethasone palmitate large porous particles: A controlled release formulation for lung delivery of corticosteroids
}

Alain N'Guessan, Elias Fattal, David Chapron, Claire Gueutin, Armand Koffi, Nicolas Tsapis

\section{To cite this version:}

Alain N'Guessan, Elias Fattal, David Chapron, Claire Gueutin, Armand Koffi, et al.. Dexamethasone palmitate large porous particles: A controlled release formulation for lung delivery of corticosteroids. European Journal of Pharmaceutical Sciences, 2018, 113, pp.185-192. 10.1016/j.ejps.2017.09.013 . hal-02323727

\section{HAL Id: hal-02323727 \\ https://hal.science/hal-02323727}

Submitted on 22 Oct 2019

HAL is a multi-disciplinary open access archive for the deposit and dissemination of scientific research documents, whether they are published or not. The documents may come from teaching and research institutions in France or abroad, or from public or private research centers.
L'archive ouverte pluridisciplinaire HAL, est destinée au dépôt et à la diffusion de documents scientifiques de niveau recherche, publiés ou non, émanant des établissements d'enseignement et de recherche français ou étrangers, des laboratoires publics ou privés. 
Dexamethasone palmitate large porous particles: a controlled release formulation for lung delivery of corticosteroids

Alain N'Guessan ${ }^{a, b}$, Elias Fattal ${ }^{a}$, David Chapron ${ }^{a}$, Claire Gueutin ${ }^{a}$, Armand Koffi $^{b}$, Nicolas Tsapis ${ }^{a}$.

${ }^{a}$ Institut Galien Paris-Sud, CNRS, Univ. Paris-Sud, Université Paris-Saclay, 92296 ChâtenayMalabry, France.

${ }^{b}$ University Félix Houphouet-Boigny, School of Pharmacy, Abidjan, Côte d'Ivoire

\section{Corresponding authors :}

N. Tsapis, Institut Galien Paris-Sud, CNRS, Univ. Paris-Sud, Université Paris-Saclay, 92296 Châtenay-Malabry, France, nicolas.tsapis@u-psud.fr

Graphical abstract

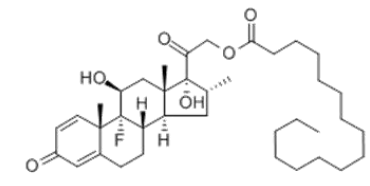

Dexamethasone palmitate (DXP) Lipidic prodrug of dexamethasone (DXM)

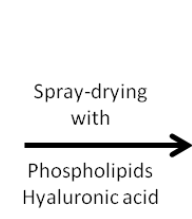
Hyaluronic acid

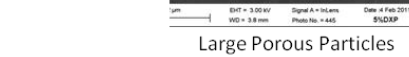
$D 50=13 \mu \mathrm{m}, \rho=0.05 \pm 0.01 \mathrm{~g} / \mathrm{cm}^{3}$ FPF $40 \%$, AF $30 \%$
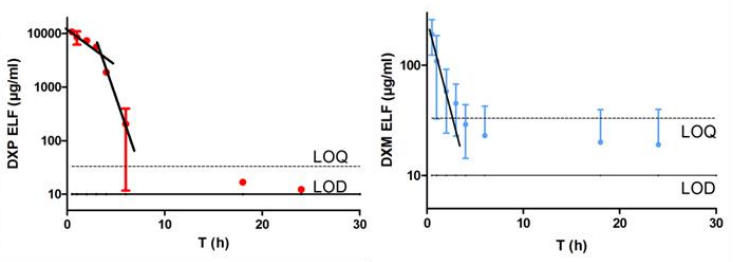

Sustained lung release after administration to rats 


\section{Abstract}

We have optimized a formulation of a prodrug of dexamethasone (DXM), dexamethasone palmitate (DXP) for pulmonary delivery as a dry powder. Formulations were prepared by spray drying DXP with 1,2-Dipalmitoyl-sn-Glycero-3-Phosphocholine (DPPC) and Hyaluronic Acid (HA) as excipients. Large porous particles around $13 \mu \mathrm{m}$ were produced with a tap density of $0.05 \mathrm{~g} / \mathrm{cm}^{3}$ and a Fine particle fraction around $40 \%$. The palmitate moiety favors DXP insertion into DPPC bilayers therefore limiting its in vitro release as shown by differential scanning calorimetry. After administering DXP powder intratracheally to rats by insufflation, bronchoalveolar lavage fluid (BALF) and blood samples were collected up to $24 \mathrm{~h}$ and DXP and DXM concentrations were determined by HPLC analysis after extraction. PK parameters were evaluated according to a non-compartmental model. We observe that DXP remains for up to $6 \mathrm{~h}$ in the epithelial lining fluid (ELF) of the lungs at very high concentration. In addition, DXP concentration decreases according to two characteristic times. Consequently, DXM can be detected at rather important concentration in ELF up to $24 \mathrm{~h}$. The passage of DXP from the lungs to the bloodstream is very poor whereas DXM seems to be absorbed in the blood more easily. These results suggest that once administered DXP undergoes two different processes: hydrolysis into DXM due to the presence of esterases in the lungs and distribution in the lung tissue. This formulation appears promising to reduce systemic exposure and prolong the effect of the drug locally.

Keywords: Dexamethasone palmitate; Dexamethasone; large porous particles; spray drying; lung delivery; pharmacokinetics. 


\section{Introduction}

Asthma is a chronic inflammatory disorder of the airways, usually associated with airway hyper-responsiveness and variable airflow obstruction, that can be reversed either spontaneously or under treatment (Asthma, 2014). Allergen sensitization is an important risk factor for asthma (Bateman et al., 2008) and for the past 40 years, the prevalence of asthma has increased in all countries in parallel with that of allergy. It is estimated that as many as 300 million people of all ages in the world suffer from asthma (Asthma, 2014). Anti-asthmatic treatments can be administered via different routes of administration such as parenteral or oral (prednisone) but the pulmonary route is often preferred, as it allows delivering the medication right to the site of action where it is needed. Anti-asthmatic treatments vary depending on the extent of the disease but for quick relief they mostly consist in a combination of beta2 adrenergic agonists and corticosteroids. Beta2 adrenergic agonists such as albuterol, levalbuterol, metaproterenol or terbutaline are used as bronchodilators helping to relax airway muscles within 5 minutes (Spina, 2014). They lead to an increase of the airflow, facilitating patient breathing. Beta2 adrenergic agonists help relieving asthma symptoms for 3 to 6 hours. Corticosteroids such as beclomethasone propionate, fluticasone furoate or propionate, budesonide, ciclesonide, or flunisolide are used for their anti-inflammatory effects and required several administrations per day. Inhaled corticosteroids are effective in the treatment of asthma because of their ability to interfere with multiple inflammatory processes involved in the asthmatic pathology (Allen et al., 2003; Barnes and Pedersen, 1993; Crim et al., 2001). Inhalation offers advantages for the treatment of asthma using corticosteroids as compared with the systemic route. It helps, with efficiency and optimal tolerance; to locally treat a condition that requires the use of high doses of active product by systemic route. The inhaled corticosteroids allow a rapid onset of action and induce fewer side effects than does administration by other routes (Beck-Broichsitter et al., 2009; Boisson et al., 2014). However, these benefits are often associated with limited lung deposition and short duration of action because of respiratory protection mechanisms (Hanania et al., 1995). Thus, the ideal inhaled corticosteroid should have: long residence time in the lung; intrinsic activity; low oral bioavailability and high systemic clearance resulting in negligible systemic side effects. However, most currently marketed inhaled corticosteroids still require several daily administrations (Burgt et al., 2000; Czock et al., 2005; Hübner et al., 2005). To modify 
corticoids residence time in the lungs, an appropriate formulation can be developed to deliver these molecules.

Lung delivery can be achieved by nebulization of drug solutions (Rodrigo, 2015) or suspensions of nanoparticles (Sahib et al., 2011), or using either metered dose inhalers(Berger et al., 2014) or dry powders for inhalation (Chawes et al., 2014). Current formulation approaches of corticosteroid dry powders consist in micronizing the active pharmaceutical ingredient and blend it with lactose as a carrier, which characteristics can be optimized (Buttini et al., 2008; Donovan and Smyth, 2010; Hoppentocht et al., 2014). Alternatively, large porous particles (LPPS), characterized by geometric sizes greater than 4-5 $\mu \mathrm{m}$ and mass densities lower than $0.4 \mathrm{~g} / \mathrm{cm}^{3}$, have been introduced for both local and systemic applications by the pulmonary route to the lungs (Cruz et al., 2011; Edwards and Dunbar, 2002; Edwards et al., 1997; Gervelas et al., 2007; Pham et al., 2015). A major advantage of LPPs relative to conventional inhaled therapeutic aerosol particles is their aerosolization efficiency (Dunbar et al., 1998; Edwards and Dunbar, 2002). This allows the supply of large drug masses using a simple inhalation device (Edwards, 2002). These characteristics suggest that inhalation of LPPs may be beneficial in the treatment of asthma by delivering the corticosteroids directly to the primary site of inflammation to achieve therapeutic local drug concentrations with low systemic exposure.

To favor prolonged efficacy of the corticosteroid it appeared interesting to combine LPPs with a corticosteroid prodrug. We have chosen to use a prodrug of dexamethasone since this corticosteroid is often used a reference to evaluate the efficacy of other molecules (Kelly, 2009). Dexamethasone palmitate is of particular interest since its aliphatic chain may help modulating its release from lipid-based LPPs. As excipients, dipalmitoyl-snglycero-3phosphatidylcholine (DPPC) and hyaluronic acid (HA) have been chosen due to their biocompatibility, biodegradability and ability to yield porous particles (Gomez-Gaete et al., 2008). DXP encapsulation into DPPC-HA microparticles was optimized by spray drying, varying DXP concentration with respect to the lipid content. Physico-chemical characterization of the powders will be presented as well as aerosolization efficacy using a multistage liquid impiger and drug release in sink conditions. Once the formulation optimized, pharmacokinetics of DXP and its active metablite dexamthasone (DXM) were determined in plasma and epithelial lung fluid after intratracheal administration of the DXP powder by insufflation. 
The aim of the work is therefore to optimize the formulation of DXP by spray-drying into large porous particles and to evaluate their pharmacokinetics and lung distribution in vivo in rats. We expect the delivery of a lipidic corticosteroid prodrug will allow to prolong drug residence in the lungs. 


\section{Materials and methods}

\subsection{Materials}

Dexamethasone palmitate (DXP) was provided by Interchim (France), Dexamethasone (DXM) and Dexamethasone acetate (DXA) were provided by ChemosGmbH (Germany), Testosterone decanoate (TC) was provided by Sigma-Aldrich (France), 1,2-dipalmitoyl-sn-glycero-3phosphatidylcholine (DPPC) by Corden Pharma (Switzerland) and hyaluronic acid, sodium salt 95\% (HA) (MW = $1000 \mathrm{kDa}$ ) by Acros Organics. Acetonitrile was of high-performance liquid chromatography (HPLC) grade. All chemicals used were of analytical grade. Organic solvents were provided by Carlo Erba (Italy) and were of analytical grade when not specified. Water was purified using a RIOS/MilliQ system from Millipore (France).

\subsection{Microparticles preparation}

DXP-loaded microparticles were prepared by spray drying using a mini spray-dryer BÜCHI B290 (France) equipped with a $0.7 \mathrm{~mm}$ diameter two-fluid nozzle, which operates in a cocurrent mode according to conditions detailed in Table 1. An aqueous solution of HA was prepared by dissolving $200 \mathrm{mg}$ of HA into $150 \mathrm{ml}$ of water upon magnetic stirring at room temperature. An ethanolic solution was prepared by dissolving DPPC and DXP into $350 \mathrm{ml}$ of ethanol absolute to obtain a final amount of $800 \mathrm{mg}$ of lipophilic compounds. The weight percent of DXP was varied between 0 and $15 \%$. Ethanolic and aqueous solutions were then mixed at a ratio of $70 / 30(\mathrm{v} / \mathrm{v})$ prior to spray-drying and the mixture maintained under moderate stirring while fed into the spray-dryer. The yield was calculated as a percentage of the mass of the powder collected divided by the initial mass of solids in the solution prior to spray-drying. 
Table 1. Operational conditions used for spray-drying.

\begin{tabular}{|c|c|}
\hline Feed flow rate $(\mathrm{mL} / \mathrm{min})$ & 17 \\
\hline Inlet temperature $(\stackrel{\circ}{ } \mathrm{C})$ & $150 \pm 2$ \\
\hline Outlet temperature $(\stackrel{\circ}{ } \mathrm{C})$ & $55 \pm 4$ \\
\hline Aspiration setting (\%) & $100\left(35 \mathrm{~m}^{3} / \mathrm{h}\right)$ \\
\hline Air-flow rate (L/h) & 414 \\
\hline
\end{tabular}

\subsection{Particle size distribution}

Powders size distributions were measured by light diffraction using a Mastersizer 2000 equipped with a Scirocco dry disperser (Malvern Instruments, France) at a dispersing pressure of 3 bars. The refractive index used was 1.5. Data obtained were expressed in terms of the particle diameter at $10 \%, 50 \%$ and $90 \%$ of the volume distribution (D10, D50 and D90 respectively). The span of the volume distribution, a measure of the width of the distribution relative to the median diameter was calculated according to Eq 1. A large span is indicative of a more heterogeneous size distribution. Values presented are the average of at least 3 determinations.

$$
\text { Span }=\frac{D 90-D 10}{D 50}(\text { Eq. 1) }
$$

\subsection{Tap density and aerodynamic diameter}

Powder tap density $(\rho)$ was determined using a tapping apparatus (Pharma test PT-TD1). Accurately weighed powder samples were filled into a $5 \mathrm{ml}$ graduated cylinder and the height measured following 1000 taps which allowed the density to plateau (Pharmacopoeia, 2013). Assuming an efficient packing, the tap density of monodisperse spheres is approximately a $21 \%$ underestimate of the true particle density due to the void spaces between particles. Although polydispersity may reduce the void volume between particles, this is probably counterbalanced by an imperfect packing (Vanbever et al., 1999). Measurements were performed in duplicate. 


\subsection{Scanning electron microscopy}

Scanning electron microscopy (SEM) was performed using a LEO1530 microscope (LEO Electron Microscopy Inc., Thornwood, USA) operating between 1 and $3 \mathrm{kV}$ with a filament current of about $0.5 \mathrm{~mA}$. Powder samples were deposited on carbon conductive double-sided tape (Euromedex, France) and were coated with a palladium-platinum layer of about $4 \mathrm{~nm}$ using a Cressington sputter-coater $208 \mathrm{HR}$ with a rotary planetary-tilt stage, equipped with a MTM-20 thickness controller.

\subsection{Differential scanning calorimetry (DSC)}

The DSC analysis was performed on hydrated samples (0 to $15 \%$ DXP) on a differential scanning calorimeter (DSC7, Perkin-Elmer, USA). About $10 \mathrm{mg}$ of powder was hydrated with $100 \mu \mathrm{l}$ of water $12 \mathrm{~h}$ before experiments. Then about $15 \mathrm{mg}$ of hydrated samples were loaded into $40 \mu \mathrm{l}$ aluminum pans and analyzed. The DSC runs were conducted from 20 to $80{ }^{\circ} \mathrm{C}$ at a rate of $5^{\circ} \mathrm{C} / \mathrm{min}$. Calibration was achieved using Indium $\left(\mathrm{T}_{\text {onset }}=156.60^{\circ} \mathrm{C}\right)$ as well as $\mathrm{n}$-decane $\left(\mathrm{T}_{\text {onset }}=-29.66^{\circ} \mathrm{C}\right)$. Experiments were performed at least in duplicate. Enthalpies were normalized with respect to DPPC weight in the sample.

\subsection{Aerosolization characterization}

The aerodynamic particle size distribution was determined using a Multi-Stage Liquid Impinger (MSLI). A dry powder inhalation device (Aerolizer ${ }^{\circledR}$, Novartis, Switzerland) was filled with a size 3 capsule made of hydroxypropylmethyl cellulose (HPMC, LGA France) containing the powder. The test was carried out at $60 \mathrm{~L} / \mathrm{min}$ for $4 \mathrm{~s}$ with a ratio of pressure $\mathrm{P} 3 / \mathrm{P} 2<0.5$. Five capsules loaded with an average of $10 \mathrm{mg}$ powder were taken for each test. Drug deposition in the device, the piece mimicking the throat, the four stages and the filter was determined by HPLC analysis. For accuracy, each test was repeated three times. The particles with aerodynamic diameters smaller than $5 \mu \mathrm{m}$ and $3.1 \mu \mathrm{m}$ were determined by interpolation from the cumulative amount of respective stages and considered as the fine particle fraction (FPF) (\%) and as the alveolar particle fraction (AF) (\%) expressed as a percentage of the loaded/nominal dose (Hinds, 1999; Pharmacopoeia, 2013). 


\subsection{DXP release from microparticles}

Drug release from microparticles prepared with 5\% DXP was carried out the following way: 25 $\mathrm{mg}$ of microparticles were accurately weighted, resuspended in $25 \mathrm{~mL}$ of PBS (corresponding to a final DXP concentration of $50 \mu \mathrm{g} / \mathrm{mL}$ ) and the preparation was protected from light and placed at $37{ }^{\circ} \mathrm{C}$ under magnetic stirring. At each time point, the suspension was vortexed and $1 \mathrm{~mL}$ was collected. $100 \mu \mathrm{L}$ of the vortexed sample was diluted to the tenth $(1 / 10)$ in acetonitrile, in order to determine total DXP concentration. The remaining $900 \mu \mathrm{L}$ were centrifuged (13.000 rpm, $15 \mathrm{~min}$ ) (Mini Spin Eppendorf centrifuge) and $100 \mu \mathrm{L}$ of the supernatant were diluted to the tenth in acetonitrile, to determine DXP concentration in the supernatant. After filtration ( $0.45 \mu \mathrm{m}$ PVDF filter), samples were stored at $4^{\circ} \mathrm{C}$ until analysis by HPLC as described below. Experiments were performed in duplicate.

\subsection{Pharmacokinetics and bronchoalveolar distribution study}

Sprague Dawley male rats with average weight of $300 \mathrm{~g}$ were obtained from Envigo (Gannat, France). All animal experiments were carried out in accordance with the Principles of Laboratory Animal Care as adopted and propagated by the EU guidelines for Animal Experiments (86/609/EEC and 2010/63/EU) and Legislation in force in France (Decree No. 2013-118 of February 1, 2013). They were housed 4 per cage while on study in accordance to EEC guidelines. The light/dark cycle was $12 \mathrm{~h} / 12 \mathrm{~h}$. The temperature in the animal room was ambient room temperature of approximately $25^{\circ} \mathrm{C}$ and the ambient humidity was in the range of approximately $35-60 \%$. Animals were allowed access to food and water ad libitum throughout the duration of the study.

Rats were anesthetized with an intraperitoneal injection of a mixture of ketamine $\left(100 \mathrm{mg} . \mathrm{kg}^{-}\right.$ $\left.{ }^{1}\right)$ and xylazine (10 mg. $\mathrm{kg}^{-1}$ ) and then intratracheally administered with $3 \mathrm{mg}$ of DXP powder corresponding to $150 \mu \mathrm{g}$ of DXP using a Microsprayer (PennCentury, Philadelphia, PA) (Kohno et al., 2010; Neuhaus et al., 2011; Wijagkanalan et al., 2008). Powder was delivered through the insufflation device by rapidly pushing a $2 \mathrm{~cm}^{3}$ bolus of air through the device. After administration, rats were supported vertically for $1 \mathrm{~min}$. Blood and bronchoalveolar fluid were collected at $\mathrm{t}=30 \mathrm{~min}, 1 \mathrm{~h}, 2 \mathrm{~h}, 3 \mathrm{~h}, 4 \mathrm{~h}, 6 \mathrm{~h}, 18 \mathrm{~h}$ and $24 \mathrm{~h}$ after administration. For each rat, blood was taken at 3 different time points via the jugular vein (Khoder et al., 2010; Nave et al., 2010). At least 3 different rats were used for each time point. Before taking the blood, the rats were anesthetized by isoflurane inhalation. Blood samples $(1 \mathrm{~mL})$ were collected in citrated 
tubes and immediately separated at $4000 \mathrm{rpm}$ during $5 \mathrm{~min}$ at room temperature $\left(20^{\circ} \mathrm{C}\right)$ using a microcentrifuge (Minispin Eppendorf). Plasma was aspirated and frozen at $-80^{\circ} \mathrm{C}$ until further analysis. Bronchalveolar lavage fluid (BALF) was collected by lavaging lungs three times with $1 \mathrm{~mL}$ of PBS per intratracheal lavage. The lungs were massaged and the fluid withdrawn immediately and collected in centrifuge tube kept on ice. The rats were euthanized by cardiac puncture under deep isoflurane anesthesia before BALF collection. The trachea was cannulated using an 18 gauge needle adaptor for subsequent injection and retrieval of BALF. Then BALF collected was frozen at $-80^{\circ} \mathrm{C}$ until further analysis. PK of DXP and DXM in plasma and ELF were evaluated according to a non compartmental model. PK parameters were calculated using GraphPad Prism (Version 5 software for windows, Inc.). The AUC was calculated from time zero to the last blood collection time (24h).

\subsection{Extraction of DXP or DXM from plasma and BALF.}

Extraction of DXP and DXM from either plasma or BALF was performed as follows (Alhareth et al., 2012). In an amber glass tube to protect DXP and DXM from light (REF), 100 $\mu \mathrm{L}$ of plasma or BALF and $100 \mu \mathrm{L}$ of internal standards (testosterone decanoate (TD) for DXP and dexamethasone acetate (DXA) for DXM, both at $4 \mu \mathrm{g} / \mathrm{mL}$ in acetonitrile were added and vortexed during 30 seconds. Then $3 \mathrm{~mL}$ of a chloroform:methanol mixture $(9: 1, v: v)$ were added in the tube. Sample was vortexed during $3 \mathrm{~min}$ to obtain protein precipitation and then was centrifuged during $10 \mathrm{~min}$ at 10,000 rpm using a min centrifuge (minispin eppendorf, France). The organic phase in the bottom was transferred into a clean amber vial and evaporated to dryness under a stream of nitrogen at $30^{\circ} \mathrm{C}$. The residue was then reconstituted into $100 \mu \mathrm{L}$ of acetonitrile and vortexed prior to analysis using HPLC conditions described below.

\subsection{HPLC method}

Quantification of DXM or DXP concentration in microparticles, in PBS (release), in plasma and in BALF was performed by HPLC. A Water ${ }^{\mathrm{TM}} 2707$ autosampler chromatographic system was employed equipped with a Waters ${ }^{\text {TM }} 1525$ binary HPLC pump, a Waters ${ }^{\text {TM }} 2998$ photodiode array detector, and a Waters ${ }^{\mathrm{TM}}$ Breeze software. The analysis was performed at $240 \mathrm{~nm}$ using a SymmetryShield ${ }^{\mathrm{TM}}$ RP18 column $(5 \mu \mathrm{m}, 250 \times 4.6 \mathrm{~mm}$; Waters, Saint-Quentin-en-Yvelines, 
France). Column temperature was maintained at $40{ }^{\circ} \mathrm{C}$ using a column Heater (Model 1500, Waters Corporation). The mobile phase was composed by a mixture of acetonitrile and milliQ water: $85 / 15 \mathrm{v} / \mathrm{v}$ for DXP and 35/65 v/v for DXM. The mobile phase flow rate was $1.2 \mathrm{~mL} / \mathrm{min}$, the injection volume was $50 \mu \mathrm{L}$ and the run time was $30 \mathrm{~min}$. Retention times were $24 \mathrm{~min}$ and $9 \mathrm{~min}$ for DXP and DXM, respectively, $21 \mathrm{~min}$ for TD and $26 \mathrm{~min}$ for DXA. Each sample was analyzed twice, once with DXP quantification method, second with DXM quantification method. For quantification from in vitro samples, the developed method showed good linearity between 0.5 and $250 \mu \mathrm{g} / \mathrm{mL}\left(y=50896 x-1239 ; r^{2}=0.998\right)$ for DXP and 0.3 and 260 $\mu \mathrm{g} / \mathrm{mL}\left(y=43920 x+9731 ; r^{2}=0.9995\right)$ for DXM. For quantification from in vivo samples, limits of detection and quantifications were determined. 


\section{Results and discussion}

\section{1- Powder characteristics}

DXP microparticles were obtained by spray-drying by varying the DXP content up to $15 \%$ $(w / w)$, We obtained white and fluffy powders. Polydisperse aggregated spherical microparticles exhibiting some roughness were observed by SEM, with a tendency to aggregation as DXP content increased (Figure 1).
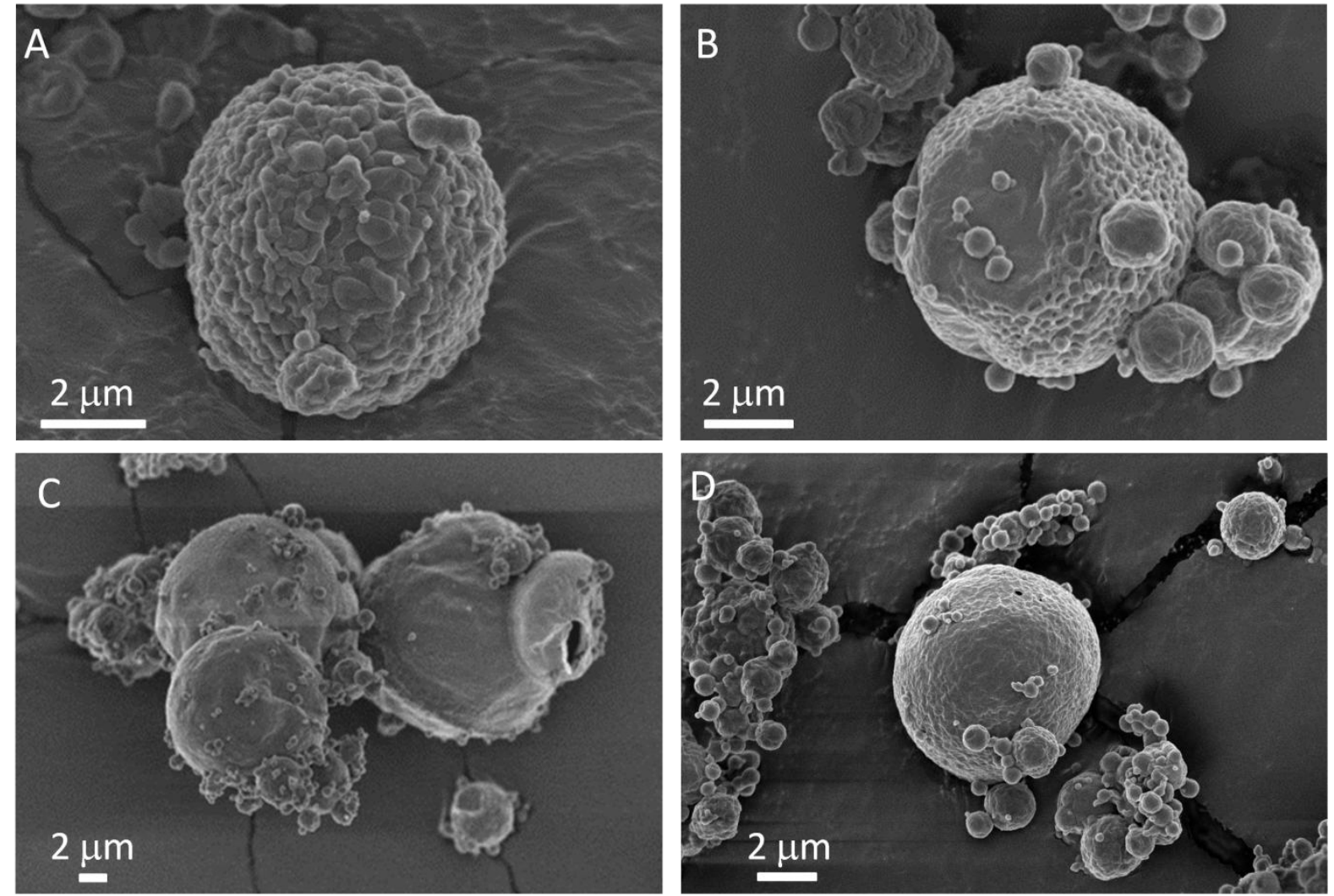

Figure 1: SEM images of typical microparticles obtained by spray drying. Image A corresponds to DPPC-HA microparticles exempt of DXP, Images B to D correspond to 5, 10 and 15\% DXP $(w / w)$, respectively.

Laser diffraction granulometry confirmed SEM observations with a median volume geometric diameter D50 between 12.3 and $13.7 \mu \mathrm{m}$, and a span between 2 and 3, with no obvious trend as DXP content increases (Figure 2A and 2B). The tap density varies between 0.053 and $0.066 \mathrm{~g} / \mathrm{cm}^{3}$, independently of DXP content (Figure $2 \mathrm{C}$ ). The low tap density indicates microparticles present some porosity as observed previously with DXM using the same excipients (Gomez-Gaete et al., 2008). The powder yield however showed a decrease from $34 \%$ to $26 \%$ as DXP concentration increased from 0 to $15 \%$. This yield decrease is associated with an increase in powder cohesion. This result is in agreement with previous ones obtained 
when incorporating dexamethasone in a similar formulation (Gomez-Gaete et al., 2008): the higher the drug content, the more cohesive the powder.
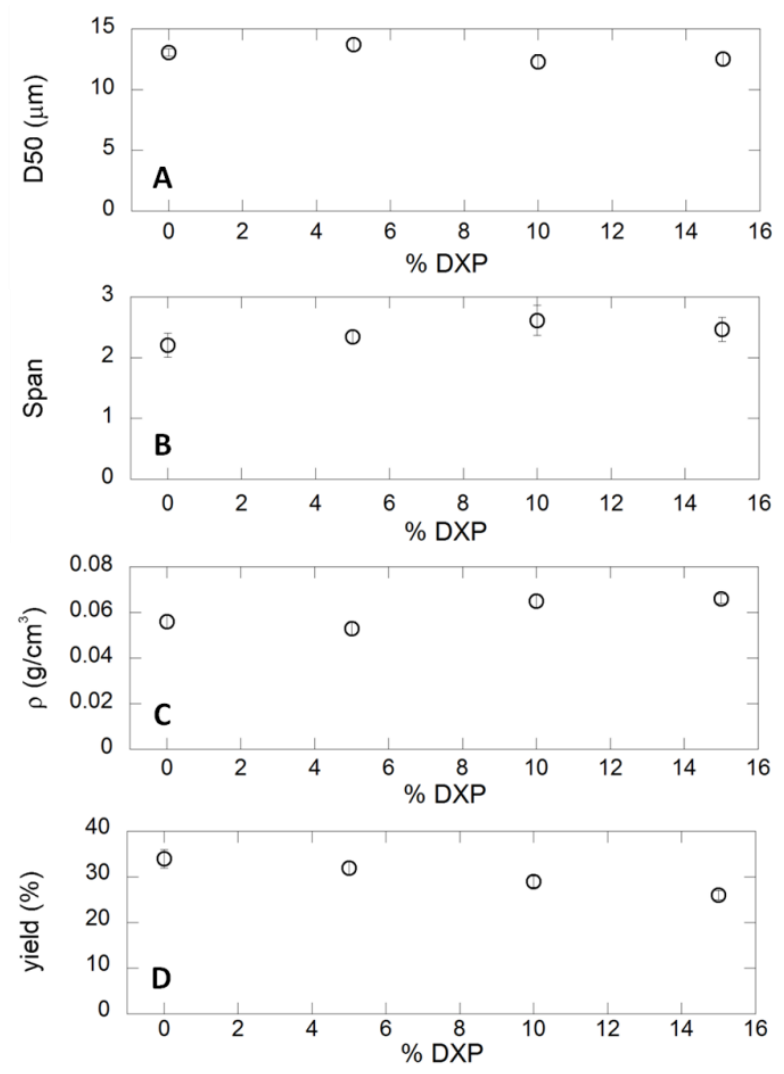

Fig 2 : Microparticles characteristics in terms of median volume geometric diameter (D50, A), span (B), tap density (C) and yield (D) as a function of the weight percent of DXP in the formulation. Results are presented as mean $\pm S D(n=3)$.

The aerodynamic behavior of the powder was then evaluated in terms of emitted fraction, fine particle fraction and alveolar fraction. The emitted fraction was $98 \pm 2 \%$ independently of the formulation. Contrary to microparticle median size, span or tap density, a clear trend can be observed for both the FPF and the AF that decrease as DXP weight percent increases (Figure 3). The FPF and $\mathrm{AF}$ varies from $40 \pm 7 \%$ to $14 \pm 1 \%$ and from $30 \pm 6 \%$ to $7 \pm 1 \%$, respectively. This decrease is most probably related to powder cohesion as described above. 


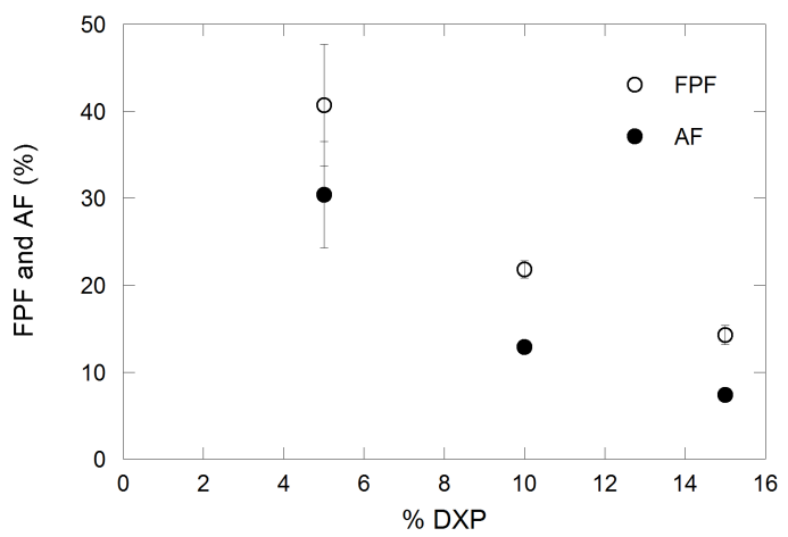

Fig 3: Fine particle fractions (FPF) and Alveolar fractions (AF) of DXP microparticles determined using an MSLI as a function of DXP weight percent in the formulation. Values are presented as the mean \pm SD $(n=3)$.

Given these results, we decided to focus on microparticles formulated with 5\% DXP which lead to the highest FPF and AF with a good yield.

\subsection{In vitro release of DXP}

DXP release from 5\% DXP microparticles was followed during several days. About $2 \%$ of DXP was immediately released after vortexing. This burst effect corresponds to a concentration of $1 \mu \mathrm{g} / \mathrm{mL}$. Then a gradual and rather slow release was observed for 21 days from $2 \%$ to about 5\% (Figure 4). It should be noted that no dexamethasone was detected during this experiment. Although the release conditions are very different from what would happen in vivo, results indicate a sustained release from the microparticles. In vivo, we expect that esterases and lipases would accelerate considerably the release, as observed by others (Lu et al., 2009). In addition, one should note that the solubility of DXP in PBS was not measurable. The fact that we detect DXP in our release experiment might be favoured by the presence of DPPC. Although this specific phospholipid is very hydrophobic, it possesses a critical micellar concentration of $0.46 \mathrm{nM}$ at $20^{\circ} \mathrm{C}$ (Smith and Tanford, 1972). The very few micelles probably help solubilising DXP. 


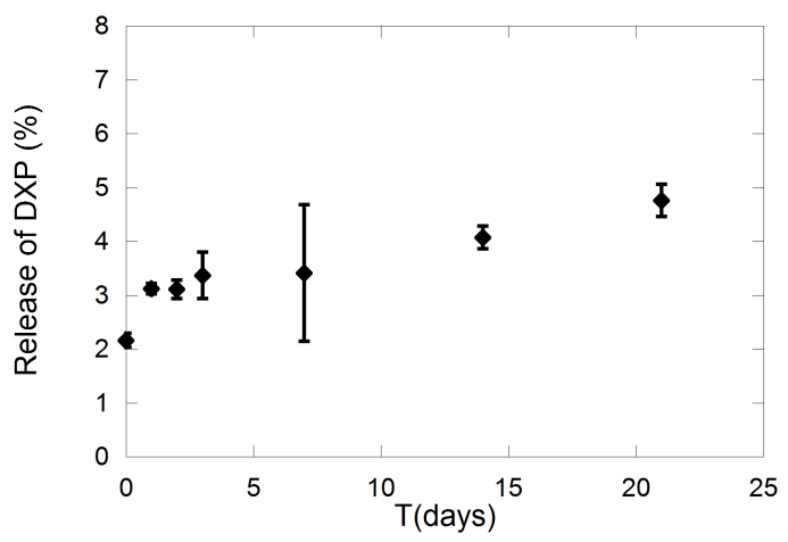

Fig 4: In vitro DXP release from $5 \%$ DXP microparticles in PBS at $37^{\circ} \mathrm{C}$.

\subsection{Differential scanning calorimetry (DSC)}

To better understand DXP release, DSC was performed on hydrated samples to assess the possible interactions between DPPC and DXP (0\% to 15\%). For hydrated microparticles made without DXP, the DSC thermogram exhibit a very flat pretransition of DPPC due to the interaction with $\mathrm{HA}$ and the typical main phase transition of DPPC at Tonset $=42.3^{\circ} \mathrm{C}$ with an enthalpy $\Delta \mathrm{H}=45.8 \mathrm{~J} / \mathrm{g}$ (Figure 5). This result is in agreement with those obtained for similar microparticles (Gomez-Gaete et al., 2008). When hydrated, lipid bilayers swell forming typical liquid crystalline phases of DPPC (Gomez-Gaete et al., 2008). As DXP content increases, the pretransition does not appear anymore. The onset temperature of the main DPPC transition shifts down to $39^{\circ} \mathrm{C}$ and the enthalpy of DPPC decreases (Figure 5). At $15 \%$ DXP, one can also observe the appearance of a thermal event with a $\mathrm{T}_{\text {onset }}$ of $55.7{ }^{\circ} \mathrm{C}$. We do believe this thermal event corresponds to a phase transition of DXP, although nothing can be found in the literature. Indeed when DSC experiments were conducted with higher DXP content, the peak became more important (data not shown). The combination of the decrease of the onset temperature of DPPC and of its enthalpy (Fig 6) is the signature of the insertion of DXP within the DPPC bilayer as observed for cholesterol (Kessel et al., 2001). This insertion is rather logical since DXP possesses an aliphatic chain of 16 carbons, the exact same length as DPPC aliphatic chains. DXP insertion within bilayers further explains the slow release observed upon incubation. 

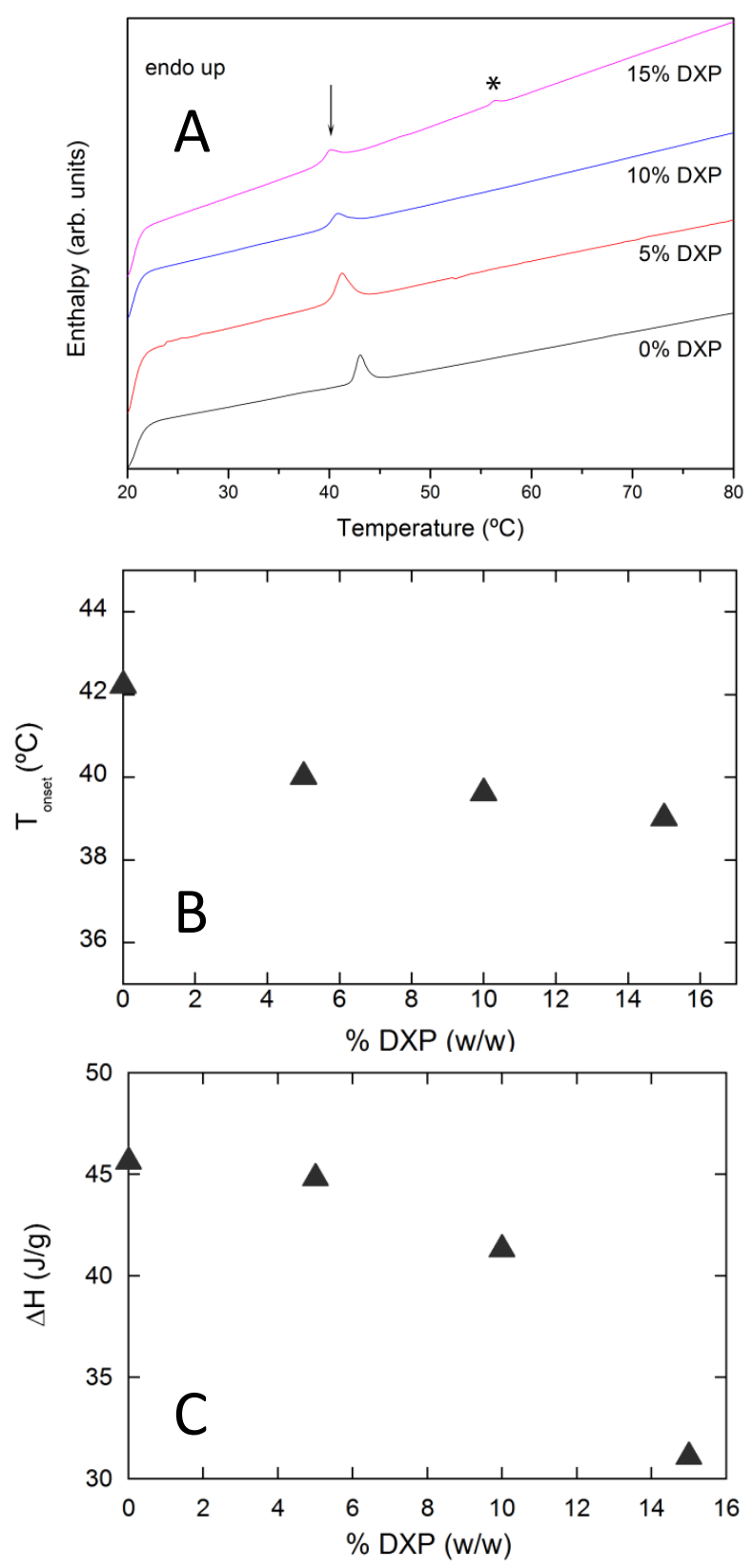

Fig 5: DSC thermograms obtained from hydrated powders upon heating at $5^{\circ} \mathrm{C} / \mathrm{min}$ with different concentrations of DXP (0 to $15 \%)$. The arrow indicates the position of the DPPC main transition around $40^{\circ} \mathrm{C}$, whereas the star indicates what we believe corresponds to a transition associated to DXP (Panel A). Variation of the onset temperature (B) and of the enthalpy (C) of DPPC main transition as a function of DXP concentration in the powder. Values are presented as mean $\pm S D(n=3)$. Error bars are smaller than the size of the symbols. 


\subsection{In vivo experiments}

The extraction method for biological samples was satisfactory with extraction yields for DXP of $84 \pm 2 \%$ for extraction from BALF, and $66 \pm 7 \%$ for extraction from plasma, as well as for DXM with $87 \pm 4 \%$ extraction from BALF and $83 \pm 7 \%$ extraction from plasma. Limits of detection (LOD) and quantification (LOQ) for each molecule are presented in Table 2. The results of DXP and DXM obtained in BALF were converted to epithelial lining fluid (ELF) concentrations according to the theoretical volume of ELF reported in the literature (30 $\mu \mathrm{L} / \mathrm{kg})$ and to the volume of PBS used for bronchoalveolar lavage $(1 \mathrm{~mL})$. Thus, for a rat of $300 \mathrm{~g}$, the dilution factor determined by calculation was 333 (Gontijo et al., 2014).

Table 2: Limits of detection and quantification of the different molecules after extraction from plasma or BALF.

\begin{tabular}{lllll}
\hline \multicolumn{2}{l}{ Parameters } & Plasma & BALF & ELF \\
\hline \multirow{2}{*}{ DXM } & LOQ $(\mu \mathrm{g} / \mathrm{mL})$ & 0.133 & 0.1 & 33 \\
& LOD $(\mu \mathrm{g} / \mathrm{mL})$ & 0.04 & 0.03 & 10 \\
\multirow{2}{*}{ DXP } & LOQ $(\mu \mathrm{g} / \mathrm{mL})$ & 0.17 & 0.1 & 33 \\
& LOD $(\mu \mathrm{g} / \mathrm{mL})$ & 0.06 & 0.03 & 10 \\
\hline
\end{tabular}

All PK parameters are presented in Table 3 for both DXP and DXM. The results of DXP and DXM concentrations obtained in ELF are presented in figure 6 as semi-log plots. The maximal concentration of DXP in the ELF is obtained 30 min after administration with a value $C_{\text {DXP-ELF- }}$ $\max =10794 \mu \mathrm{g} / \mathrm{mL}$. It corresponds to about $65 \%$ of the theoretical initial concentration given the administered dose. Then the DXP concentration decreases and can be described by three different phases. The first phase occurs between $30 \mathrm{~min}$ and $3 \mathrm{~h}$ corresponding to a slow decrease from $10794 \mu \mathrm{g} / \mathrm{mL}$ (65\% of initial theoretical concentration) to $5657 \mu \mathrm{g} / \mathrm{mL}$ (34\% of initial theoretical concentration). This first phase can be fitted by a single exponential decrease $y=y_{A} \exp \left(-k_{1} / t\right)$ with $k_{1}=0.247 h^{-1}$ and a characteristic half-time $t_{1 / 2 A}=\frac{\ln 2}{k_{1}}=2.8 \pm 0.4 \mathrm{~h}$. The second phase corresponds to a faster decrease between $3 \mathrm{~h}$ and $6 \mathrm{~h}$ from $5657 \mu \mathrm{g} / \mathrm{mL}$ to $204 \mu \mathrm{g} / \mathrm{mL}$, which corresponds to $1.2 \%$ of the initial theoretical concentration. This second decrease can be fitted by a single exponential decrease $y=y_{B} \exp \left(-k_{2} / t\right)$ with $k_{2}=1.09 h^{-1}$ and a characteristic half-time $t_{1 / 2 B}=\frac{\ln 2}{k_{2}}=0.63 \pm 0.01 \mathrm{~h}$. The last phase suggests a slow elimination of 
DXP from ELF although it cannot be modeled since the last two concentrations at $18 \mathrm{~h}$ and $24 \mathrm{~h}$ were below the LOQ of DXP in ELF. For DXM in ELF, one can observe a rapid decrease of concentration between $30 \mathrm{~min}$ and $4 \mathrm{~h}$, then the concentration remains stable but very low below the LOQ. The decrease can be fitted by a single exponential decrease $y=y_{A} e x p\left(-k_{1} / t\right)$ with $k_{1}=0.743 \mathrm{~h}^{-1}$ and a characteristic half-time $\mathrm{t}_{1 / 2}=\frac{\ln 2}{k_{2}}=0.93 \pm 0.20 \mathrm{~h}$. The area under the curve (AUC) of DXP in ELF was $26703 \mu \mathrm{g} . \mathrm{h} / \mathrm{mL}$ whereas for DXM the exposure was much lower with an AUC around $674 \mu \mathrm{g} . \mathrm{h} / \mathrm{mL}$ (Table 3).
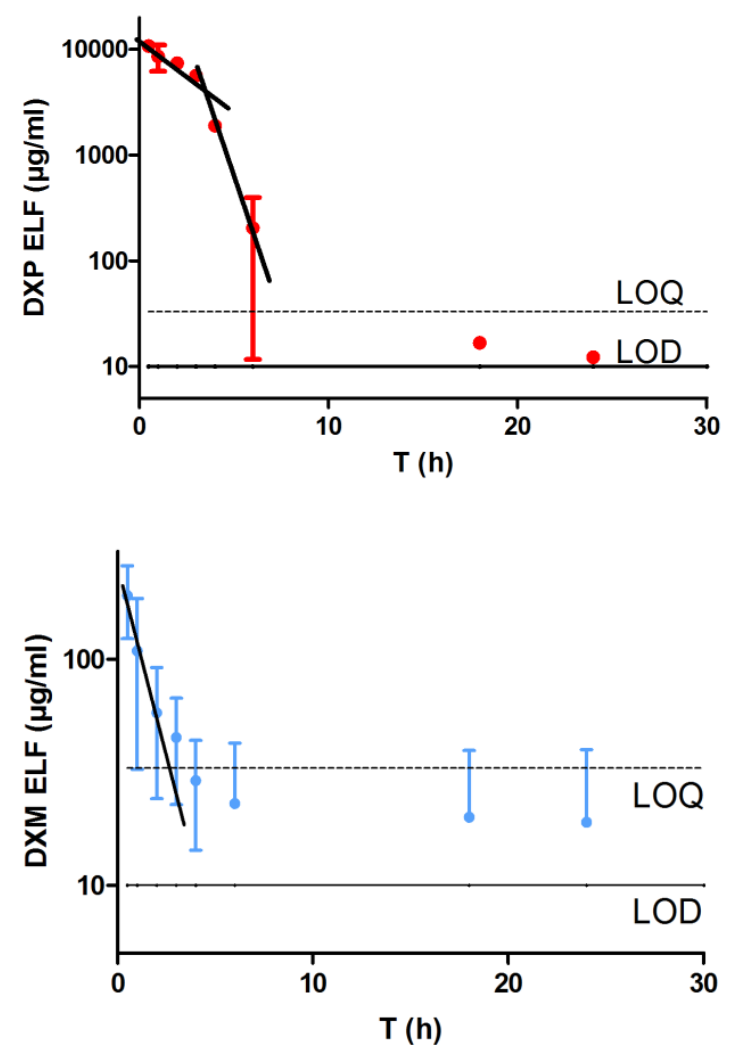

Figure 6: Concentration of DXP (top) and DXM (bottom) in ELF after intratracheal insufflation of 3mg of DXP microparticles (DXP dose $=150 \mu \mathrm{g}$ ). LOQs are represented as dashed curves and LOD as full curves. The LOD is $10 \mu \mathrm{g} / \mathrm{mL}$. Data are presented as mean \pm SEM (Standard error of the mean), $n=3$.

The concentrations found in the plasma were very low for DXP with values between the LOQ and the LOD (Figure 7). The systemic exposure to DXP in the plasma therefore cannot be determined. For DXM, the concentrations found in plasma are low but above the LOQ and 
seem to follow a two-step decrease (Figure 7). The first decrease takes place between 30min and $4 \mathrm{~h}$ and can be fitted by a single exponential decrease $y=y_{A} \exp \left(-k_{1} / t\right)$ with $k_{1}=0.207 h^{-1}$ and a characteristic half-time $t_{1 / 2 \mathrm{~A}}=\frac{\ln 2}{k_{1}}=3.34 \pm 0.33 \mathrm{~h}$. The second phase corresponds to a slower decrease between $4 \mathrm{~h}$ and $24 \mathrm{~h}$ and can be fitted by a single exponential decrease $y=$ $\mathrm{y}_{\mathrm{B}} \exp \left(-\mathrm{k}_{2} / \mathrm{t}\right)$ with $\mathrm{k}_{2}=0.0182 \mathrm{~h}^{-1}$ and a characteristic half-time $\mathrm{t}_{1 / 2 \mathrm{~B}}=\frac{\ln 2}{k_{2}}=38 \mathrm{~h} \pm 10 \mathrm{~h}$. The plasmatic exposure to DXM can be quantified by calculating the AUC and one finds $4.89 \mu \mathrm{g} . \mathrm{h} / \mathrm{mL}$ (Table 3).
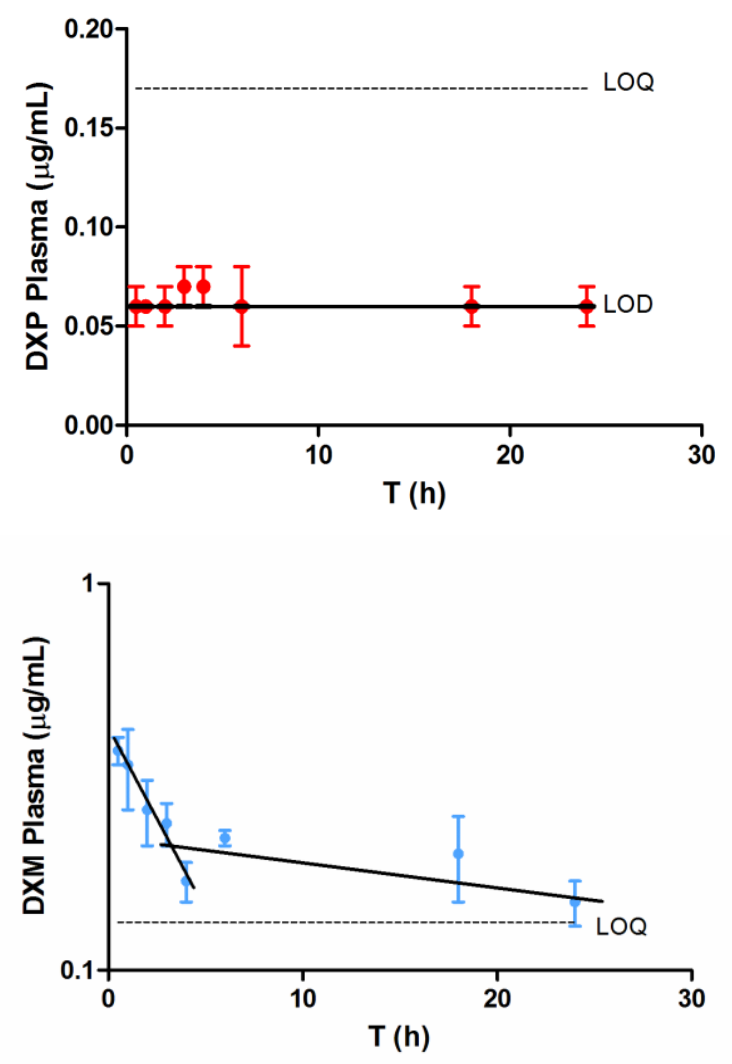

Figure 7: Concentration of DXP (top) and DXM (bottom) in plasma after intratracheal insufflation of 3mg of DXP microparticles (DXP dose $=150 \mu \mathrm{g}$ ). LOQs are represented as dashed curves and LOD as full curves. The LOD of DXM in plasma was not presented as all values were above the LOQ. Data are presented as mean \pm SEM (Standard error of the mean), $n=3$.

The ELF/plasma AUC ratio is around 138 for DXM and could not be calculated for DXP. This suggests a very pronounced local delivery and a rather low passage of molecules from the lungs to the blood stream. Experimental concentrations could be explained by three main phenomena as described in Figure 8: powder solubilization, DXP hydrolysis into DXM, DXP/DXM distribution in lung tissue and DXP/DXM passage in the blood stream. Indeed, the 
first part of the DXP curve in ELF may correspond to the solubilization of particles to release DXP molecules along with hydrolysis of DXP into DXM occuring due to the presence of esterases in the ELF (Basu et al., 1988; Deimling et al., 1983). The fast decrease of DXP concentration in ELF probably corresponds to DXP distribution in lung tissue. This distribution is favored by DXP lipophilicity. DXP lipophilicity also explains the very low DXP concentration detected in the bloodstream (Derendorf et al., 1998; Edsbäcker and Johansson, 2006; Georgitis, 1999). One can notice that DXM is cleared faster from ELF ( $t_{1 / 2 A}$ of about $\left.1 \mathrm{~h}\right)$ than from the plasma $\left(t_{1 / 2 A}\right.$ of about $3 h$ ) due to the route of administration and the physicochemical properties of the molecule. DXM is absorbed in the blood more efficiently than DXP since it is less lipophilic. The second decrease of DXM concentration observed in the plasma with a very long half-life of $38 \mathrm{~h}$ most probably corresponds to the elimination phase of the drug. One can hypothesize that the lung tissue contains a very high content of DXP that is slowly converted into DXM which in turn is absorbed in the bloodstream (Johnson, 1996).

Table 3: PK parameters (mean \pm SEM) after intratracheal insufflations of $3 \mathrm{mg}$ of DXP powder corresponding to a dose of $150 \mu \mathrm{g}$ of DXP (93 $\mu \mathrm{g}$ of DXM).

\begin{tabular}{|c|c|c|c|}
\hline Parameters & & ELF & Plasma \\
\hline \multirow{7}{*}{ DXM } & $\mathrm{C}_{\max }(\mu \mathrm{g} / \mathrm{mL})$ & 191 & 0.37 \\
\hline & $t_{\max }(h)$ & 0.5 & 0.5 \\
\hline & $\mathrm{AUC}(\mu \mathrm{g} . \mathrm{h} / \mathrm{mL})$ & 674 & 4.89 \\
\hline & AUC/Dose $(\mathrm{h} / \mathrm{mL})$ & 7.22 & 0.053 \\
\hline & $t_{1 / 2 A}(h)$ & $0.93 \pm 0.20$ & $3.34 \pm 0.3$ \\
\hline & $t_{1 / 2 B}(h)$ & NA & $38 \pm 10$ \\
\hline & $\mathrm{AUC}_{\text {ELF }} / \mathrm{A} \cup \mathrm{C}_{\text {Plasma }}$ & 138 & \\
\hline \multirow{6}{*}{ DXP } & $\mathrm{C}_{\max }(\mu \mathrm{g} / \mathrm{mL})$ & 10794 & NA \\
\hline & $t_{\max }(h)$ & 0.5 & NA \\
\hline & $t_{1 / 2 A}(h)$ & $2.8 \pm 0.4$ & NA \\
\hline & $t_{1 / 2 B}(h)$ & $0.63 \pm 0.01$ & NA \\
\hline & $\mathrm{AUC}(\mu \mathrm{g} \cdot \mathrm{h} / \mathrm{mL})$ & 26703 & NA \\
\hline & AUC/Dose $(\mathrm{h} / \mathrm{mL})$ & 178 & NA \\
\hline
\end{tabular}


$C_{\text {max }}$ maximal concentration in ELF and in plasma; $t_{\max }$ time of maximal concentration in ELF and in plasma; AUC, area under the curve of ELF and plasma concentrations ; $t_{1 / 2}$, terminal half-life in ELF and in plasma.

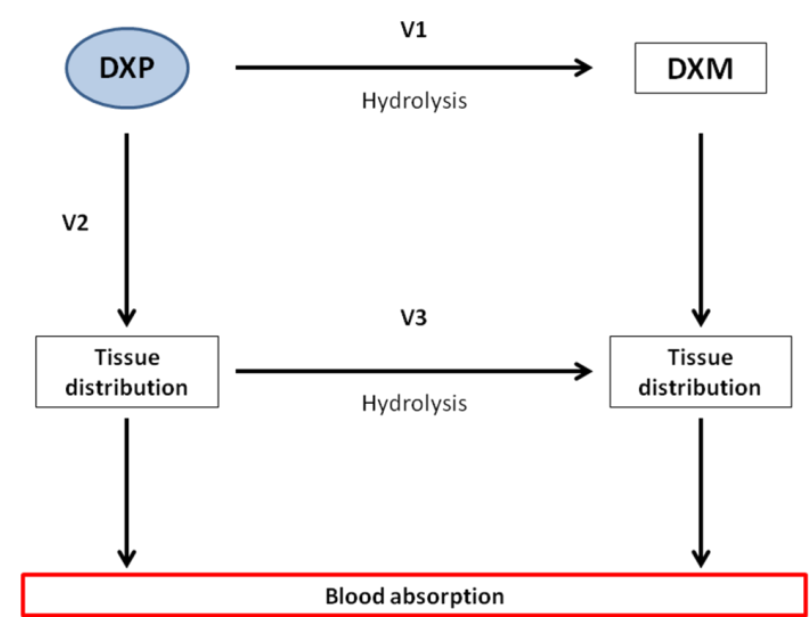

Figure 8: Schematic description the different phenomena occuring after DXP microparticles are delivered to the lungs.

Our analytical conditions were not sufficient to quantify properly DXM in ELF but this molecule could be detected up to $24 \mathrm{~h}$ suggesting a prolonged local effect. DXM and DXP were not dosed in the lung tissue since it is difficult to fully exsanguinate the animal and therefore to separate what accounts for tissue from what accounts for remaining blood. Although inhaled corticosteroids are prescribed daily, the literature is very scarce about comparison between ELF and plasma concentrations after lung administration on animal models. An article by Mo et al. (Mo et al., 2014) presents the pharmacokinetic study of prednisolone administered by intratracheal instillation at the dose of $1 \mathrm{mg} / \mathrm{kg}$ to guinea pigs of about $300 \mathrm{~g}$. They compared ethanol/water $3 / 1(\mathrm{v} / \mathrm{v})$ solutions of prednisolone and L-carnitine esters of prednisolone. The resulting AUC of prednisolone after prednisolone succinate-L-carnitine administration was around $100 \mu \mathrm{g} . \mathrm{h} / \mathrm{L}=0.1 \mu \mathrm{g} . \mathrm{h} / \mathrm{mL}$. If one divides this value by the dose of prednisolone the $A U C_{\text {PRED }} /$ dose $=0.0033 \mathrm{~h} / \mathrm{mL}$, whereas we find $0.053 \mathrm{~h} / \mathrm{mL}$ for $D X M$ in plasma, signature of a higher systemic exposure for rather similar doses $(1 \mathrm{mg} / \mathrm{kg}$ equivalent prednisolone and $0.3 \mathrm{mg} / \mathrm{kg}$ equivalent DXM). Concentrations in ELF could not be compared since these authors measured drug in tissue and not in the lavage fluid. However prednisolone 
succinate-L-carnitine could be quantified in the lung tissue up to $6 \mathrm{~h}$ after administration. These results are in agreement with what we have obtained. Since Mo et al. have shown an anti-asthmatic efficacy, our microparticles of DXP might hold great potential to prevent inflammation in the lungs.

\section{Conclusion}

We have optimized a formulation of a prodrug of dexamethasone, dexamethasone palmitate for pulmonary delivery as a dry powder. In vitro drug release is rather slow with less than $5 \%$ of DXP in the supernatant after 21 days, and arises from DXP insertion within the DPPC bilayers once powders were hydrated. Although a thorough model of what is happening after DXP microparticle lung administration cannot be proposed, one can notice that the prodrug (DXP) remains for up to $6 \mathrm{~h}$ in the ELF at very high concentration, that the drug itself (DXM) can be detected at rather important concentration in ELF up to $24 \mathrm{~h}$. The passage of DXP from the lungs to the bloodstream is very poor whereas DXM seems to be absorbed in the blood more easily. Overall however the systemic exposure seems low compared to the lung exposure which suggests limited side effects. Therapeutic efficacy of this formulation remains to be evaluated in the future by using asthmatic animal models. The strategy of using a lipophilic prodrug could be extended to other molecules to promote long residence time in the lungs while reducing drug systemic exposure.

\section{Acknowledgments:}

A. N'Guessan PhD fellowship was supported by University Félix Houphouet-Boigny, Côte d'Ivoire, Univ Paris-Sud, Châtenay-Malabry and Institut Galien Paris-Sud CNRS UMR 8612. Authors would like to thank V. Domergue-Dupont, L. Aragão-Santiago, C. Ruge and D.D. Pham for support with animal experiments. Institut Galien Paris-Sud is a member of the Laboratory of Excellence LERMIT supported by a grant from ANR (ANR-10-LABX-33). The authors would also like to acknowledge the financial support provided by COST-European Cooperation in Science and Technology, to the COST Action MP1404: Simulation and pharmaceutical technologies for advanced patient-tailored inhaled medicines (Siminhale). 


\section{References}

Allen, D.B., Bielory, L., Derendorf, H., Dluhy, R., Colice, G.L., Szefler, S.J., 2003. Inhaled corticosteroids: past lessons and future issues. The Journal of Allergy and Clinical Immunology 112 , S1-40.

Asthma, G.I.f., 2014. Global Initiative for Asthma. Global strategy for asthma management and prevention. GINA.

Barnes, P.J., Pedersen, S., 1993. Efficacy and Safety of Inhaled Corticosteroids in Asthma. American Review of Respiratory Disease 148, S1-S26.

Basu, A., Glew, R.H., Evans, R.W., Bandik, G., 1988. Isolation and characterization of a fatty acyl esterase from rat lung. Archives of Biochemistry and Biophysics 261, 384-393.

Bateman, E.D., Hurd, S.S., Barnes, P.J., Bousquet, J., Drazen, J.M., FitzGerald, M., Gibson, P., Ohta, K., O'Byrne, P., Pedersen, S.E., Pizzichini, E., Sullivan, S.D., Wenzel, S.E., Zar, H.J., 2008. Global strategy for asthma management and prevention: GINA executive summary. Eur Respir J 31, 143-178.

Beck-Broichsitter, M., Gauss, J., Packhaeuser, C.B., Lahnstein, K., Schmehl, T., Seeger, W., Kissel, T., Gessler, T., 2009. Pulmonary drug delivery with aerosolizable nanoparticles in an ex vivo lung model. Int J Pharm 367, 169-178.

Berger, W.E., Bensch, G.W., Weinstein, S.F., Skoner, D.P., Prenner, B.M., Shekar, T., Nolte, H., Teper, A.A., 2014. Bronchodilation with mometasone furoate/formoterol fumarate administered by metered-dose inhaler with and without a spacer in children with persistent asthma. Pediatr Pulmonol 49, 441-450.

Boisson, M., Jacobs, M., Grégoire, N., Gobin, P., Marchand, S., Couet, W., Mimoz, O., 2014. Comparison of Intrapulmonary and Systemic Pharmacokinetics of Colistin Methanesulfonate (CMS) and Colistin after Aerosol Delivery and Intravenous Administration of CMS in Critically III Patients. Antimicrob Agents Ch 58, 7331-7339.

Burgt, J.A.V., Busse, W.W., Martin, R.J., Szefler, S.J., Donnell, D., 2000. Efficacy and safety overview of a new inhaled corticosteroid, QVAR (hydrofluoroalkane-beclomethasone extrafine inhalation aerosol), in asthma. J Allergy Clin Immun 106, 1209-1226.

Buttini, F., Colombo, P., Wenger, M.P., Mesquida, P., Marriott, C., Jones, S.A., 2008. Back to basics: the development of a simple, homogenous, two-component dry-powder inhaler formulation for the delivery of budesonide using miscible vinyl polymers. J Pharm Sci 97, 1257-1267.

Chawes, B.L., Govoni, M., Kreiner-Moller, E., Vissing, N.H., Poorisrisak, P., Mortensen, L., Nilsson, E., Bisgaard, A., Dossing, A., Deleuran, M., Skytt, N.L., Samandari, N., Piccinno, A., Sergio, F., Ciurlia, G., Poli, G., Acerbi, D., Singh, D., Bisgaard, H., 2014. Systemic exposure to inhaled beclometasone/formoterol DPI is age and body size dependent. Respir Med 108, 1108-1116.

Crim, C., Pierre, L.N., Daley-Yates, P.T., 2001. A review of the pharmacology and pharmacokinetics of inhaled fluticasone propionate and mometasone furoate. Clinical Therapeutics 23, 1339-1354.

Cruz, L., Fattal, E., Tasso, L., Freitas, G.C., Carregaro, A.B., Guterres, S.S., Pohlmann, A.R., Tsapis, N., 2011. Formulation and in vivo evaluation of sodium alendronate spray-dried microparticles intended for lung delivery. J Control Release 152, 370-375.

Czock, D., Keller, D.F., Rasche, F.M., Häussler, U., 2005. Pharmacokinetics and Pharmacodynamics of Systemically Administered Glucocorticoids. Clinical Pharmacokinetics 44, 61-98. 
Deimling, O.v., Müller, M., Eisenhardt, E., 1983. The non-specific esterases of mouse lung. Histochemistry 78, 271-284.

Derendorf, H., Hochhaus, G., Meibohm, B., Möllmann, H., Barth, J., 1998. Pharmacokinetics and pharmacodynamics of inhaled corticosteroids. J Allergy Clin Immun 101, S440-S446.

Donovan, M.J., Smyth, H.D., 2010. Influence of size and surface roughness of large lactose carrier particles in dry powder inhaler formulations. Int J Pharm 402, 1-9.

Dunbar, C.A., Hickey, A.J., Holzner, P., 1998. Dispersion and Characterization of Pharmaceutical Dry Powder Aerosols. Kona 16, 7-45.

Edsbäcker, S., Johansson, C.-J., 2006. Airway Selectivity: An Update of Pharmacokinetic Factors Affecting Local and Systemic Disposition of Inhaled Steroids. Basic \& Clinical Pharmacology \& Toxicology 98, 523-536.

Edwards, D.A., 2002. Delivery of biological agents by aerosols. AIChE Journal 48, 2-6.

Edwards, D.A., Dunbar, C., 2002. Bioengineering of Therapeutic Aerosols. Annual Review of Biomedical Engineering 4, 93-107.

Edwards, D.A., Hanes, J., Caponetti, G., Hrkach, J., Ben-Jebria, A., Eskew, M.L., Mintzes, J., Deaver, D., Lotan, N., Langer, R., 1997. Large porous particles for pulmonary drug delivery. Science 276, 1868-1871.

Georgitis, J.W., 1999. The 1997 Asthma Management Guidelines and therapeutic issues relating to the treatment of asthma. National Heart, Lung, and Blood Institute. Chest 115, 210217.

Gervelas, C., Serandour, A.L., Geiger, S., Grillon, G., Fritsch, P., Taulelle, C., Le Gall, B., Benech, H., Deverre, J.R., Fattal, E., Tsapis, N., 2007. Direct lung delivery of a dry powder formulation of DTPA with improved aerosolization properties: Effect on lung and systemic decorporation of plutonium. J Control Release 118, 78-86.

Gomez-Gaete, C., Tsapis, N., Silva, L., Bourgaux, C., Besnard, M., Bochot, A., Fattal, E., 2008. Supramolecular organization and release properties of phospholipid-hyaluronan microparticles encapsulating dexamethasone. Eur J Pharm Biopharm 70, 116-126.

Gontijo, A.V.L., Brillault, J., Grégoire, N., Lamarche, I., Gobin, P., Couet, W., Marchand, S., 2014. Biopharmaceutical Characterization of Nebulized Antimicrobial Agents in Rats: 1. Ciprofloxacin, Moxifloxacin, and Grepafloxacin. Antimicrob Agents Ch 58, 3942-3949.

Hanania, N.A., Chapman, K.R., Kesten, S., 1995. Adverse effects of inhaled corticosteroids. The American Journal of Medicine 98, 196-208.

Hinds, W.C., 1999. Aerosol Technology: Properties, Behavior, and Measurement of Airborne Particles, 2nd Edition. John Wiley \& Sons.

Hoppentocht, M., Hagedoorn, P., Frijlink, H.W., de Boer, A.H., 2014. Technological and practical challenges of dry powder inhalers and formulations. Adv Drug Deliv Rev 75, 18-31.

Hübner, M., Hochhaus, G., Derendorf, H., 2005. Comparative Pharmacology, Bioavailability, Pharmacokinetics, and Pharmacodynamics of Inhaled Glucocorticosteroids. Immunology and Allergy Clinics of North America 25, 469-488.

Johnson, M., 1996. Pharmacodynamics and pharmacokinetics of inhaled glucocorticoids. J Allergy Clin Immun 97, 169-176.

Kelly, H.W., 2009. Comparison of inhaled corticosteroids: an update. Ann Pharmacother 43, 519-527.

Kessel, A., Ben-Tal, N., May, S., 2001. Interactions of Cholesterol with Lipid Bilayers: The Preferred Configuration and Fluctuations. Biophysical Journal 81, 643-658. 
Khoder, M., Tsapis, N., Domergue-Dupont, V., Gueutin, C., Fattal, E., 2010. Removal of residual colonic ciprofloxacin in the rat by activated charcoal entrapped within zinc-pectinate beads. Eur J Pharm Sci 41, 281-288.

Kohno, M., Haramoto, M., Nakajima, O., Yang, L., Hinotsu, S., Yokohira, M., Imaida, K., Kawakami, K., 2010. Antedrug budesonide by intrapulmonary treatment attenuates bleomycin-induced lung injury in rats with minimal systemic adverse effects. Biological \& Pharmaceutical Bulletin 33, 1206-1211.

Lu, X., Howard, M.D., Talbert, D.R., Rinehart, J.J., Potter, P.M., Jay, M., Leggas, M., 2009. Nanoparticles containing anti-inflammatory agents as chemotherapy adjuvants II: role of plasma esterases in drug release. AAPS J 11, 120-122.

Mo, J., Lim, L.Y., Zhang, Z.-R., 2014. I-Carnitine ester of prednisolone: Pharmacokinetic and pharmacodynamic evaluation of a type I prodrug. Int J Pharm 475, 123-129.

Nave, R., Watz, H., Hoffmann, H., Boss, H., Magnussen, H., 2010. Deposition and metabolism of inhaled ciclesonide in the human lung. Eur Respir J 36, 1113-1119.

Neuhaus, S., Seifert, L., Vautz, W., Nolte, J., Bufe, A., Peters, M., 2011. Comparison of metabolites in exhaled breath and bronchoalveolar lavage fluid samples in a mouse model of asthma. Journal of Applied Physiology 111, 1088-1095.

Pham, D.D., Gregoire, N., Couet, W., Gueutin, C., Fattal, E., Tsapis, N., 2015. Pulmonary delivery of pyrazinamide-loaded large porous particles. Eur J Pharm Biopharm 94, 241-250.

Pharmacopoeia, E., 2013. European Pharmacopoeia (Ph. Eur.), Strasbourg.

Rodrigo, G.J., 2015. Advances in acute asthma. Curr Opin Pulm Med 21, 22-26.

Sahib, M.N., Darwis, Y., Peh, K.K., Abdulameer, S.A., Tan, Y.T., 2011. Rehydrated sterically stabilized phospholipid nanomicelles of budesonide for nebulization: physicochemical characterization and in vitro, in vivo evaluations. Int J Nanomedicine 6, 2351-2366.

Smith, R., Tanford, C., 1972. The critical micelle concentration of L- dipalmitoylphosphatidylcholine in water and water-methanol solutions. J Mol Biol 67, 75-83.

Spina, D., 2014. Current and novel bronchodilators in respiratory disease. Curr Opin Pulm Med 20, 73-86.

Vanbever, R., Mintzes, J.D., Wang, J., Nice, J., Chen, D.H., Batycky, R., Langer, R., Edwards, D.A., 1999. Formulation and physical characterization of large porous particles for inhalation. Pharm Res 16, 1735-1742.

Wijagkanalan, W., Higuchi, Y., Kawakami, S., Teshima, M., Sasaki, H., Hashida, M., 2008. Enhanced Anti-Inflammation of Inhaled Dexamethasone Palmitate Using Mannosylated Liposomes in an Endotoxin-Induced Lung Inflammation Model. Molecular Pharmacology 74, 1183-1192. 